\title{
Compression and evaluation of extended release matrix pellets prepared by the extrusion/spheronization process into disintegrating tablets
}

\author{
Raveendra Pai ${ }^{1, *}$, Kanchan Kohli², Birendra Shrivastava ${ }^{3}$ \\ ${ }^{1}$ Formulation Development Services, Matrix Laboratories Ltd., Hyderabad, India, ${ }^{2}$ Department of Pharmaceutics, \\ Faculty of Pharmacy, Jamia Hamdard University, New Delhi, India, ${ }^{3}$ Faculty of Pharmaceutical Sciences, \\ Jaipur National University, Jaipur, India
}

\begin{abstract}
In this study, a novel approach for compression of matrix pellets into disintegrating tablets has been studied in an attempt to overcome the issues pertaining to rupture of polymer coat during compression of reservoirtype pellets. Extended release matrix pellets were prepared by the extrusion/spheronization technique using commercially available aqueous dispersions of ethyl cellulose, acrylic polymers and sodium alginate at $10 \%$, $20 \%$ and $30 \% \mathrm{w} / \mathrm{w}$ levels. Sertraline hydrochloride was used as the model drug and an in vitro release profile of $12 \mathrm{~h}$ was targeted. Tablets containing matrix pellets were prepared by the direct compression process. Acceptance Value, a pharmacopeial test, was applied to study the uniformity of drug distribution. Effect of compression force (2-6 kN), extrusion screen aperture size, diluent blend composition and pellet percentage on drug release and acceptance value were studied. As polymer is uniformly distributed within each pellet, the drug release pattern from uncompressed pellets was comparable to compressed tablets. Surface morphological changes due to calcium chloride treatment were observed using Scanning electron microscopy. The pellet segregated from the surface of the tablet was found to be flattened in the direction of applied compression force with minor deformities. In conclusion, matrix pellets can constitute an alternative approach to reservoir-type pellets in obtaining disintegrating tablets for extended delivery of drugs.
\end{abstract}

Uniterms: Pellets/extended release/evaluation. Pellets/obtention. Pellets/compression. Extrusion/spheronization technique.

Nesse trabalho, estudou-se nova abordagem para a compressão de matrizes de péletes em comprimidos desintegrantes, com o intuito de resolver os problemas relativos à ruptura do polímero de revestimento durante a compressão dos péletes do tipo reservatório. Matrizes de péletes de liberação estendida foram preparadas pela técnica de extrusão/esferonização, utilizando dispersões aquosas comercialmente disponíveis de etil celulose, polímeros acrílicos e alginato de sódio a $10 \%, 20 \%$ e $30 \%$ p/p. O cloridrato de sertralina foi utilizado como fármaco modelo e focalizou-se no perfil de liberação in vitro de 12 horas. Os comprimidos contendo matrizes de péletes foram preparados pelo processo de compressão direta. O valor de aceitação, teste farmacopéico, foi aplicado para estudar a uniformidade de distribuição do fármaco. O efeito da força de compressão (2-6 kN), o tamanho da abertura de extrusão, a composição da mistura diluente, a porcentagem de pélete na liberação de fármaco e o valor de aceitação foram estudados. Como o polímero é uniformemente distribuído dentro de cada pélete, o padrão de liberação do fármaco dos péletes não-comprimidos foi comparável àquele dos comprimidos. As mudanças morfológicas da superfície devidas ao tratamento com cloreto de cálcio foram observadas utilizandose a microscopia eletrônica de varredura. O pélete segregado da superfície do comprimido mostrou-se plano em direção à força de compressão aplicada com menores deformidades. Em conclusão, os péletes matriz podem se constituir em abordagem alternativa para péletes do tipo reservatório na obtenção de comprimidos desintegrantes para fármacos de liberação estendida.

Unitermos: Pellets/liberação prolongada/avaliação. Pellets/obtenção. Pellets/compressão. Técnica de extrusão/ esferonização.

\footnotetext{
*Correspondence: R. Pai. Formulation Development Services, Matrix Laboratories Ltd. Plot No 34A, Bollaram Industrial Area, Jinnaram Mandal, Medak District, Hyderabad - 502325, India. E-mail: raveendrapai@yahoo.co.in
} 


\section{INTRODUCTION}

Multiple unit extended release dosage forms are preferred over single unit dosage forms as they spread uniformly throughout the gastrointestinal tract producing less variability and lower risk of local irritation due to the minute amount of drug carried (Bodmeier, 1997; Bechgaard, Nielsen, 1978). A multi-unit particulate system (MUPS) comprises a tablet dosage form wherein pellets are compressed into tablets along with appropriate excipients or cushioning agents. Conventional design of oral modified release systems involves coating of spherical pellets with polymer that regulates the rate and extent of drug release. However, there are some disadvantages with capsules, such as feasibility of tampering, difficulties in esophageal transport, and higher production costs (capsule shells), hence, such pellets are compressed into disintegrating tablets. Tablets can be prepared at a lower cost because of the higher production rate of tablet presses (Murthy, Vijaya, Ratna, 2008). In addition, tablets containing multiparticulates can be scored without losing their controlled release properties, which allows a more flexible dosing regimen (Bodmeier, 1997). The formulation challenge producing tablets from pellets is obtaining uniformity of drug content in the tablet and maintaining the desired drug release after compression. The application of compression pressure can lead to structural changes in the film coating consequently altering drug release. Most of the studies on the compression of pellets coated with ethyl cellulose and acrylic polymers have revealed damage to the coating with loss of the extended release properties (Bansal, Vasireddy, Parikh, 1993). Compression of pellets at higher force is reported to reduce the release from the tablets due to fusion of pellets (Lopez-Rodriguez et al., 1993) whereas the release of drug was found to be faster from tablets due to the brittle nature of pellets (Branka et al., 2009). Smaller pellets were reported to be less affected by the compression process than larger pellets. Use of microcrystalline cellulose and polyethylene glycol 3350 produced rapidly disintegrating tablets containing pellets, with lowest change in the drug release pattern after tableting (Torrado, Paronen, 1994). Various techniques have previously been explored in a bid to reduce the damage to rate-controlling polymer film. However, a recent study involved the use of polyethylene glycol as a cushioning agent and tablet compression at elevated temperature as an alternative to using reservoir-type pellets (Wieslaw, Jaroslaw, Ilona, 2010).

Extrusion/spheronization is an established technique for producing spherical pellets in a typical size range of between 0.5 and $2 \mathrm{~mm}$. Various polymers have been employed for preparing pellets using the extrusion spheronization technique (Pornsak et al., 2007; Helton et al., 2005). In the present study, Sertraline Hydrochloride (SRT), commonly prescribed for depressive illness, was used as the model drug. There are various reports in the literature on the side effects associated with sertraline treatment at prescribed doses, such as severe nausea, headache, diarrhea, sexual dysfunction, tremor, dizziness and fatigue (Grimsley, Jann, 1992; Dogan, 1991). A granted patent publication US 6,899,896B1 (Curatolo et al., 2005) claimed to produce better patient compliance when sertraline was released at a specified rate from a hydrogel-based dosage form. The in vitro release profile of up to $12 \mathrm{~h}$ was found to increase patient compliance and the therapeutic efficacy of sertraline. Hence in the present study, commonly used extended release polymers such as sodium alginate, aqueous dispersion of ethyl cellulose and acrylic polymers were evaluated to prepare matrix pellets (Hodsdon et al., 1995; Bhagat et al., 1990).

The objective of this study was to investigate the possibility of producing extended release matrix pellets by the extrusion/spheronization technique using Aquacoat ${ }^{\mathbb{B}}$ ECD 30, Eudragit ${ }^{\circledR}$ L 30D 55 and Eudragit ${ }^{\circledR}$ NM 30D, Sodium alginate (Keltone ${ }^{\circledR} \mathrm{LV} \mathrm{CR}$ ) as polymers to achieve in vitro drug release of up to $12 \mathrm{~h}$. These matrix pellets were compressed into tablets which should disintegrate rapidly in the dissolution medium. The study also investigated the effect of formulation variables on the uniformity of the tablet content and in vitro drug release profile.

\section{MATERIALS AND METHODS}

\section{Materials}

Sertraline hydrochloride was obtained from Matrix Laboratories Ltd, India. Sodium alginate (Keltone ${ }^{\circledR}$ LVCR) was procured from ISP Corporation India. Eudragit ${ }^{\circledR} \mathrm{L}$ 30D 55 and Eudragit ${ }^{\circledR}$ NM 30 D grades were obtained from Evonik India Ltd, Mumbai. Aquacoat ${ }^{\circledR}$ ECD, (30 $\% \mathrm{w} / \mathrm{w}$ dispersion) was obtained from FMC Biopolymer. Other excipients used in the pellet preparation and tablet compression were obtained from Matrix Laboratories Ltd, Hyderabad, India.

\section{Methods}

\section{Preparation of Matrix pellets by extrusion/ spheronization}

Matrix pellets were prepared using the various compositions shown in Table I. All the batches were of 2000 units and $100 \mathrm{mg}$ in strength. First, dry powder mixture 
was prepared by mixing sertraline, microcrystalline cellulose and hydroxypropyl cellulose (wherever required) in a laboratory scale Rapid mixer granulator [Allen Bradley 5L, USA] at slow impeller speed for around $10 \mathrm{~min}$. To granulate this blend, an aqueous dispersion of ethyl cellulose and eudragit polymers were used. Additional water, if required, was added during granulation to obtain a wet mass suitable for extrusion. While using the sodium alginate polymer, water was used as the binding liquid. The wet mass was extruded through a screen extruder [Multigran MG 55, Fugi Paudal Co Ltd Japan] equipped with a standard screen having an $0.8 \mathrm{~mm}$ diameter aperture, and rollers rotating at $30 \mathrm{rpm}$. The extrudates were transferred to the spheronizer [QJ 230T-1, Fugi Paudal Co Ltd Japan.] equipped with a crosshatch plate $[1 \mathrm{~mm}]$ and processed at $850 \mathrm{rpm}$ rotation speed for the desired time (415 $\mathrm{min})$. The spheronization time was varied according to the polymer used in the pellet preparations where the longest spheronization time was required for the composition containing $30 \% \mathrm{w} / \mathrm{w}$ sodium alginate. The resultant pellets were dried in a fluid bed dryer [Rapid dryer, Retsch, Germany] with an inlet air flow at $50{ }^{\circ} \mathrm{C}$ for about $20-30 \mathrm{~min}$. The dried pellets were sifted and retained on an ASTM \# 20 mesh $(841 \mu)$ and the fines below \# 40 mesh $(420 \mu)$ were discarded. The process yield was calculated from the quantity of fraction of dried pellets obtained after sifting (Pai, Kohli, 2011).

\section{Calcium ion complexation}

Wet pellets (about $320 \mathrm{~g}$ ) obtained from (\#F 11) composition were poured into $500 \mathrm{~mL}$ of calcium chloride solution of different concentrations $(10 \% \mathrm{w} / \mathrm{w}, 20 \% \mathrm{w} / \mathrm{w}$ and saturated solution of calcium chloride). The pellets were allowed to form gelatinous precipitate by chemical reaction between sodium alginate and calcium chloride on the surface of the pellets. The pellets were left under slow stirring for $10 \mathrm{~min}$ and then filtered, washed with distilled water and vacuum dried.

\section{Preparation of MUPS tablets}

MUPS tablets were prepared by the direct compression approach using the compositions shown in Table II. For this, $320 \mathrm{~g}$ of calcium chloride-treated pellets were mixed with microcrystalline cellulose, polyethylene glycol and crospovidone in a laboratory scale blender [Conta Blender, Bowman \& Archer] for 10 min. Finally, magnesium stearate passed through a $250 \mu \mathrm{m}$ sieve was added to the mixture and blended for $5 \mathrm{~min}$. The degree of filling of the blending vessel was $50 \%$ by volume to ensure proper mixing. The tablets of $1066 \pm 50 \mathrm{mg}$ were compressed using one set of $19.5 \times 9.5 \mathrm{~mm}$ capsule shaped, biconvex tooling on a 12-station automated single rotary compression machine [Smart Press, SRC 10i, Pacific Industries, India]. The compression machine is equipped to measure the compression forces applied to the blend. Considering the criticality of the compression process, the machine speed was set to $10 \mathrm{rpm}$. Minimum gap was maintained between the turret and the feed frame to minimize the physical stress on the blend during rotation. Tablets were compressed at different compression forces in a 2-6 kN range in order to obtain tablets with a crushing strength ranging from 80 to $240 \mathrm{~N}$.

\section{Characterization of pellets and compressed tablets}

- Density and friability

The bulk density was determined by pouring pellets into a previously weighed $10 \mathrm{ml}$ graduated glass cylinder

TABLE I - Composition of extended release matrix pellets using various polymers

\begin{tabular}{lcccccccccccc}
\hline Composition (mg) & $\# F 1$ & $\# F 2$ & $\# F 3$ & $\# F 4$ & $\# F 5$ & $\# F 6$ & $\# F 7$ & $\# F 8$ & $\# F 9$ & $\# F 10$ & $\# F 11$ & $\# F 12$ \\
\hline Sertraline & 112 & 112 & 112 & 112 & 112 & 112 & 112 & 112 & 112 & 112 & 112 & 112 \\
Microcrystalline & 166 & 134 & 102 & 166 & 134 & 102 & 166 & 134 & 102 & 176 & 144 & 112 \\
Cellulose Avicel PH102) & & & & & & & & & & & & \\
Hydroxypropyl cellulose & 10 & 10 & 10 & 10 & 10 & 10 & 10 & 10 & 10 & $\mathrm{x}$ & $\mathrm{x}$ & $\mathrm{x}$ \\
Aquacoat ECD 30 & 32 & 64 & 96 & $\mathrm{x}$ & $\mathrm{x}$ & $\mathrm{X}$ & $\mathrm{x}$ & $\mathrm{x}$ & $\mathrm{X}$ & $\mathrm{x}$ & $\mathrm{x}$ & $\mathrm{x}$ \\
Eudragit L 30D 55 & $\mathrm{x}$ & $\mathrm{x}$ & $\mathrm{x}$ & 32 & 64 & 96 & $\mathrm{x}$ & $\mathrm{x}$ & $\mathrm{x}$ & $\mathrm{x}$ & $\mathrm{x}$ & $\mathrm{x}$ \\
Eudragit NM 30D & $\mathrm{x}$ & $\mathrm{x}$ & $\mathrm{x}$ & $\mathrm{x}$ & $\mathrm{x}$ & $\mathrm{X}$ & 32 & 64 & 96 & $\mathrm{x}$ & $\mathrm{x}$ & $\mathrm{x}$ \\
Sodium Alginate & $\mathrm{x}$ & $\mathrm{x}$ & $\mathrm{x}$ & $\mathrm{x}$ & $\mathrm{x}$ & $\mathrm{X}$ & $\mathrm{x}$ & $\mathrm{x}$ & $\mathrm{x}$ & 32 & 64 & 96 \\
Water & $\mathrm{qs}$ & $\mathrm{qs}$ & $\mathrm{qs}$ & $\mathrm{qs}$ & $\mathrm{qs}$ & $\mathrm{qs}$ & $\mathrm{qs}$ & $\mathrm{qs}$ & $\mathrm{q}$ & $\mathrm{qs}$ & $\mathrm{qs}$ & $\mathrm{qs}$ \\
\hline Total Weight (mg) & $\mathbf{3 2 0}$ & $\mathbf{3 2 0}$ & $\mathbf{3 2 0}$ & $\mathbf{3 2 0}$ & $\mathbf{3 2 0}$ & $\mathbf{3 2 0}$ & $\mathbf{3 2 0}$ & $\mathbf{3 2 0}$ & $\mathbf{3 2 0}$ & $\mathbf{3 2 0}$ & $\mathbf{3 2 0}$ & $\mathbf{3 2 0}$ \\
\hline
\end{tabular}

${ }^{a}$ Weight of hydrochloride salt equivalent to $100 \mathrm{mg}$ sertraline base. qs-Quantity sufficient 
TABLE II - Composition of MUPS tablets prepared using calcium chloride-treated pellets

\begin{tabular}{lccccc}
\hline Composition (mg) & TAB \#1 & TAB \#2 & TAB \#3 & TAB \#4 & TAB \#5 \\
\hline Sertraline Pellets ${ }^{\mathrm{b}}$ & 320 & 320 & 320 & 320 & 320 \\
Microcrystalline Cellulose Avicel 102 & 646 & 446 & 446 & 263 & 78 \\
Microcrystalline Cellulose Avicel PH101 & - & 200 & - & 117 & 35 \\
Milled Avicel PH 102 & - & & 200 & - & - \\
Polyethylene glycol, 6000 & 64 & 64 & 64 & 64 & 64 \\
Crospovidone & 31 & 31 & 31 & 31 & 31 \\
Magnesium Stearate & 5 & 5 & 5 & 5 & 5 \\
\hline Total weight (mg) & $\mathbf{1 0 6 6}$ & $\mathbf{1 0 6 6}$ & $\mathbf{1 0 6 6}$ & $\mathbf{8 0 0}$ & $\mathbf{5 3 3}$ \\
Percent of pellets (\%w/w) & $\mathbf{3 0}$ & $\mathbf{3 0}$ & $\mathbf{3 0}$ & $\mathbf{4 0}$ & $\mathbf{6 0}$ \\
Acceptance Value & $\mathbf{1 8 . 7}$ & $\mathbf{1 2 . 2}$ & $\mathbf{1 4}$ & $\mathbf{N P}$ & $\mathbf{N P}$ \\
\hline
\end{tabular}

${ }^{\mathrm{b}}$ Composition \#F11, NP; Not performed

where the weight of the pellets needed to occupy a $10 \mathrm{ml}$ volume was noted. The bulk density was calculated by the ratio of weight to occupied volume.

Friability was measured using Electrolab Friability testing apparatus [Electrolab Ltd, Mumbai, India] by tumbling $10 \mathrm{~g}$ of the pellets for $4 \mathrm{~min}$ at $25 \mathrm{rpm}$. The tested pellets were gently tapped on an ASTM \# 40mesh to remove the fines generated and weight loss was measured. For testing the friability of the tablets, ten tablets were initially weighed on an analytical balance, transferred to the friabilator and run for $4 \mathrm{~min}$. The tablets were weighed after removing the powdered dust, and weight lost during testing was calculated.

- Sphericity

The sphericity of the pellets was measured using the simplest approach described by Lovgren and Lundberg (Lovgren, Lundberg, 1989), by measuring the length and width of the two dimensional image of the pellets on an optical microscope [Olympus BX55TF, Japan]. The shape factor was expressed as \% Sphericity, where $100 \%$ corresponds to a perfect circle. The longest length and breadth of the pellets were measured accurately when the pellets were rested in their most stable position. A frequency distribution of the percent ratio of length to breadth of 100 pellets was calculated and the Sphericity (S) was expressed (Eriksson, Nystrom, Aldeborn, 1993).

\section{- Hardness testing}

The force required to fracture a tablet was measured using a tablet hardness tester [Dr Schleuniger, Pharmatron $8 \mathrm{M}]$. Hardness of at least 10 tablets from each formulation was measured and reported as a range.

- Disintegration testing

The disintegration time of the tablet was tested using USP disintegration apparatus on 6 tablets from each composition. [Electrolab Disintegration Apparatus, India]. Distilled water was used as the medium at a temperature of $37{ }^{\circ} \mathrm{C}$. The time taken until no material from any of the tablets was left on the mesh was recorded.

\section{- In vitro dissolution testing}

In vitro release study of the pellets and compressed tablets was performed using acetate buffer $\mathrm{pH} 4.5$ in a dissolution test apparatus [Electrolab, Mumbai, India]. The test employed $900 \mathrm{~mL}$ of the specified buffer at $37^{\circ} \mathrm{C}$ and a USP Type II apparatus (paddle) rotating at $50 \mathrm{rpm}$. Samples were collected at 1, 2, 4, 6, 8, 10 and $12 \mathrm{~h}$ intervals and analyzed by a UV-Visible spectrophotometer [UV 2450, Shimadzu Corporation, Japan] at 273nm. Dissolution of pellets and MUPS tablets was conducted for 6 representative samples.

- Drug content analysis

To determine drug content, an amount of crushed pellets equivalent to $100 \mathrm{mg}$ of sertraline was weighed into a flask $(1000 \mathrm{~mL})$ and extracted with a minimum quantity of methanol and made up to volume with acetate buffer $\mathrm{pH} 4.5$ then sonicated for around $30 \mathrm{~min}$. UV absorbance of the solution filtered through $0.43 \mu$ filters was measured using a UV-Visible spectrophotometer [UV 2450, Shimadzu Corporation, Japan] at $273 \mathrm{~nm}(\lambda \max )$. To avoid the influence of excipients, the placebo blend was also treated similarly and kept as a blank. Standard solution was prepared by accurately weighing [Mettler Toledo, India] $100 \mathrm{mg}$ of sertraline and following a similar dilution procedure. From the absorbance of the test solution, the amount of drug in the solution was calculated.

- Acceptance Value

Acceptance Value is a test recommended by the USP 30 [2007] for evaluating content uniformity in dosage forms. As MUPS tableting involves the compression of two varying density components together, achieving content uniformity within the pharmacopoeial limits is a challenging task(Flament et al., 1994). Hence, the Acceptance Value was considered as a tool for evaluating 
uniformity and content of 10 individual tablets, measured with the method described above. Acceptance value was calculated as per the equation below.

$$
\mathrm{AV}=|\mathrm{M}-\mathrm{X}|+\mathrm{kS}
$$

Where $k$ is acceptability constant $(k=2.4$ while testing 10 tablets), $S$ is standard deviation of assay values of 10 units, $X$ is mean of the assay value. $\mathrm{M}=\mathrm{X}$ when $\mathrm{X}$ value is between $98.5-101.5 \% . \mathrm{M}=98.5$ if $\mathrm{X}$ value is below 98.5 and $M=101.5$ if $X$ value is above 101.5. Absolute value for $\mathrm{M}-\mathrm{X}$ is to be considered for calculation of Acceptance value.

- Scanning electron microscopy

Scanning electron microscope [Jeol, JSM 6380LV, Japan] was used to observe the physical properties and surface modification due to calcium ion complexation in sodium alginate-containing pellets. The untreated pellets were compared with the calcium chloride-treated pellets. Scanning electron microscopy was also used to observe the pellet distribution in the tablet and to evaluate the possible physical deformities due to the compression force applied. The pellets from the surface of compressed tablets which comes into direct contact with the tooling surface were separated carefully and observed under scanning electron microscope to observe any mechanical damage incurred during compression of the pellets.

\section{Stability evaluation of compressed tablets}

Accelerated stability studies were carried out on the MUPS tablets prepared using calcium chloride-treated pellets as per ICH recommendation. The tablets were packed in HDPE bottles and charged in a stability chamber for a $3 \mathrm{M}$ period at $40{ }^{\circ} \mathrm{C} / 75 \% \mathrm{RH}$. After completing the stability period, the tablets were evaluated for their physical and chemical attributes including drug content and drug release profile.

\section{RESULTS AND DISCUSSION}

\section{Preparation of matrix pellets and effect of polymers}

The concept of compression of matrix pellets into disintegrating tablet dosage form was derived as a response to issues pertaining to compression of reservoir-type pellets coated with polymers for extended release of drug. In reservoir-type pellets, the nature, type and amount of polymer coating has a significant impact on compressioninduced changes in the coating structure. Most of the studies on compression of pellets coated with polymers have shown damage to the coating with loss of the extended release properties due to rupture of the coat (Dashevsky, Kotler, Bodmeier, 2004) resulting in faster drug release (Sarisuta, Punpreuk, 1994). Polymers typically used in the coating of pellets are either cellulosic polymers or acrylic polymers. Hence, in the present study three commercially available aqueous dispersions of ethyl cellulose (Aquacoat ${ }^{\circledR}$ ECD 30) and acrylic polymers (Eudragit ${ }^{\circledR} \mathrm{L}$ 30D; Eudragit ${ }^{\circledR} \mathrm{NM} 30 \mathrm{D}$ ) were evaluated in an attempt to develop matrix pellets with an extended drug release profile. For this purpose an SRT, hydroxypropyl cellulose and microcrystalline cellulose blend was granulated with aqueous dispersions of polymers [Table 1] in a rapid mixer granulator. Considering the aqueous granulation process, a higher level of microcrystalline cellulose was used in the composition to facilitate the extrusion spheronization process due to its unique water absorbing and retaining characteristics (Baert, Remnon, 1993).

During initial trials of granulation, operational variables such as kneading time and spheronization time were found to have a significant impact on the length of the extrudates and shape/size of the pellets, respectively. The nature of the granules suitable for extrusion was decided based on the preliminary experiments. The process parameters were varied accordingly to obtain pellets with the desired properties. In order to involve minimum process variables while using the different polymers blending time, binder addition time, screw feeder rate and drying temperature were kept constant. Based on the property of the polymer and its quantity in the composition, the spheronization time was varied accordingly to obtain pellets with suitable properties observed visually. The properties of the pellets prepared using $10 \%, 20 \%$ and $30 \% \mathrm{w} / \mathrm{w}$ polymer are given in Table III.

While preparing pellets using a lower level of polymer, an additional quantity of water was added in order to attain the desired granule mass for extrusion. Extrusion of the blend containing a higher level of polymer $(30 \% \mathrm{w} / \mathrm{w})$ through the $0.8 \mathrm{~mm}$ screen aperture proved difficult leading to an increase in spheronization time (12-15 min). Polymer levels beyond $30 \% \mathrm{w} / \mathrm{w}$ were not evaluated as these were generating lengthy extrudates and leaving tackiness during extrusion. The drug release pattern from the pellets containing ethyl cellulose and acrylic polymer was not satisfactory (Figure 1A to 1C).

More than $85 \%$ drug release was observed within $4 \mathrm{~h}$ from the pellets containing Aquacoat ECD and Eudragit NM 30D. However, use of Eudragit L 30D 55 at a $30 \% \mathrm{w} / \mathrm{w}$ level was able to extend the drug release to $6 \mathrm{~h}$. This drug release phenomenon can be ascribed to the erosion of polymer from the surface of the pellets and release 
TABLE III - Physical characterization data of matrix pellets prepared using extrusion/spheronization process

\begin{tabular}{|c|c|c|c|c|c|c|c|c|}
\hline Polymers & Trial & $\% \mathrm{w} / \mathrm{w}$ & $\begin{array}{l}\text { Nature of } \\
\text { pellets }\end{array}$ & $\begin{array}{l}\text { Process yield } \\
(\% \mathrm{w} / \mathrm{w})\end{array}$ & $\begin{array}{l}\text { Drug content } \\
(\% \mathrm{w} / \mathrm{w})\end{array}$ & $\begin{array}{c}\text { Friability } \\
(\% \mathrm{w} / \mathrm{w})\end{array}$ & $\begin{array}{l}\text { Bulk Density } \\
(\mathrm{g} / \mathrm{mL})\end{array}$ & $\begin{array}{c}\text { Sphericity } \\
(\%)\end{array}$ \\
\hline \multirow[t]{3}{*}{ Aquacoat ECD } & F1 & 10 & $\begin{array}{l}\text { Spherical + } \\
\text { fines }\end{array}$ & 78.6 & 93.3 & 0.380 & 1.125 & $76 \pm 8 \%$ \\
\hline & $\mathrm{F} 2$ & 20 & Spherical & 86.4 & 92.1 & 0.240 & 1.095 & $84 \pm 5 \%$ \\
\hline & F3 & 30 & Spherical & 82.0 & 90.6 & 0.236 & 1.115 & $80 \pm 5 \%$ \\
\hline \multirow[t]{3}{*}{ Eudragit L 30D 55} & $\mathrm{~F} 4$ & 10 & $\begin{array}{l}\text { Spherical + } \\
\text { fines }\end{array}$ & 72.2 & 89.4 & 0.380 & 1.186 & $76 \pm 7 \%$ \\
\hline & F5 & 20 & $\begin{array}{l}\text { Spherical+ } \\
\text { fines }\end{array}$ & 84.5 & 90.6 & 0.240 & 1.182 & $81 \pm 5 \%$ \\
\hline & F6 & 30 & Spherical & 86.8 & 93.4 & 0.288 & 1.195 & $65 \pm 8 \%$ \\
\hline \multirow[t]{3}{*}{ Eudragit NM 30D } & F7 & 10 & $\begin{array}{l}\text { Almost } \\
\text { Spherical }\end{array}$ & 80.2 & 90.0 & 0.400 & 1.213 & $78 \pm 9 \%$ \\
\hline & F8 & 20 & Spherical & 82.1 & 92.3 & 0.380 & 1.236 & $82 \pm 6 \%$ \\
\hline & F9 & 30 & $\begin{array}{l}\text { Dumbbell- } \\
\text { Shaped }\end{array}$ & 72.8 & 91.1 & 0.385 & 1.328 & $65 \pm 7 \%$ \\
\hline \multirow[t]{3}{*}{ Sodium Alginate } & F10 & 10 & Spherical & 78.4 & 93.2 & 0.245 & 0.876 & $78 \pm 4 \%$ \\
\hline & F11 & 20 & Spherical & 88.9 & 92.8 & 0.210 & 0.888 & $86 \pm 5 \%$ \\
\hline & $\mathrm{F} 12$ & 30 & $\begin{array}{l}\text { Dumbbell- } \\
\text { Shaped }\end{array}$ & 76.3 & 91.2 & 0.220 & 0.877 & $72 \pm 6 \%$ \\
\hline $\begin{array}{l}\text { Calcium Chloride- } \\
\text { Treated }\end{array}$ & F10 & 20 & Spherical & - & 91.9 & 0.180 & 0.886 & $88 \pm 5 \%$ \\
\hline
\end{tabular}

of drug from the new surface becoming dissolved in dissolution media. Moreover, these polymers are not soluble in the dissolution media employed ( $\mathrm{pH} 4.5$ acetate buffer) for in vitro drug release testing. As the desired profile was not obtained in the pellet stage, compression of these pellets into MUPS tablet was not considered further.

Pellet preparation was done using sodium alginate, a widely used polymer for matrix tablets and film coatings, wherein sphsronization took slightly longer time (8-10 min). A small quantity of water (1-3 mL) was sprinkled from the top of the spheronizer to avoid rapid drying of the pellets in the spheronization chamber. The dried pellets were subjected to in vitro dissolution testing at the specified testing conditions. Complete drug release was observed within $4 \mathrm{~h}$ (Figure 1D). The rapid dissolution from the pellets could be ascribed to the formation of soluble hydrogel where drug release could occur due to both diffusion and erosion mechanisms (Pai, Kohli, 2011).

\section{Effect of calcium chloride}

Development of pellet dosage forms containing sodium alginate in the presence of calcium ions has been reported previously (Sriamornsak, Kennedy, 2006). De- layed extended release profiles of drug release have been achieved using sodium alginate in the form of beads by complexing it with calcium chloride (Patel, Nagle, Murthy, 2008). In this approach, \#F11 composition blend was granulated with water and wet spheroids were poured into a beaker containing calcium chloride solution. In vitro drug release from calcium chloride-treated pellets extended the release of sertraline to around 12h. Although there was no considerable difference in the in vitro drug release profile for the pellets treated with different concentrations of calcium chloride solution, slowest release was observed from the pellets treated with saturated calcium chloride solution (Figure 2). Cross-linking of the calcium ions generates an insoluble calcium alginate layer on the surface of the beads, reducing the entry of the dissolution media into the pellets. When treating with saturated calcium chloride solution, more calcium ions per unit area are available to react with the alginic acid moiety to form a rigid, insoluble gelatinous mass compared to the other two concentrations studied. As complexation is an instant surface phenomenon, the drug release from the saturated calcium chloride solutiontreated pellet was much closer to the desired drug release profile as illustrated in Figure 2. 



$1 \mathrm{C}$
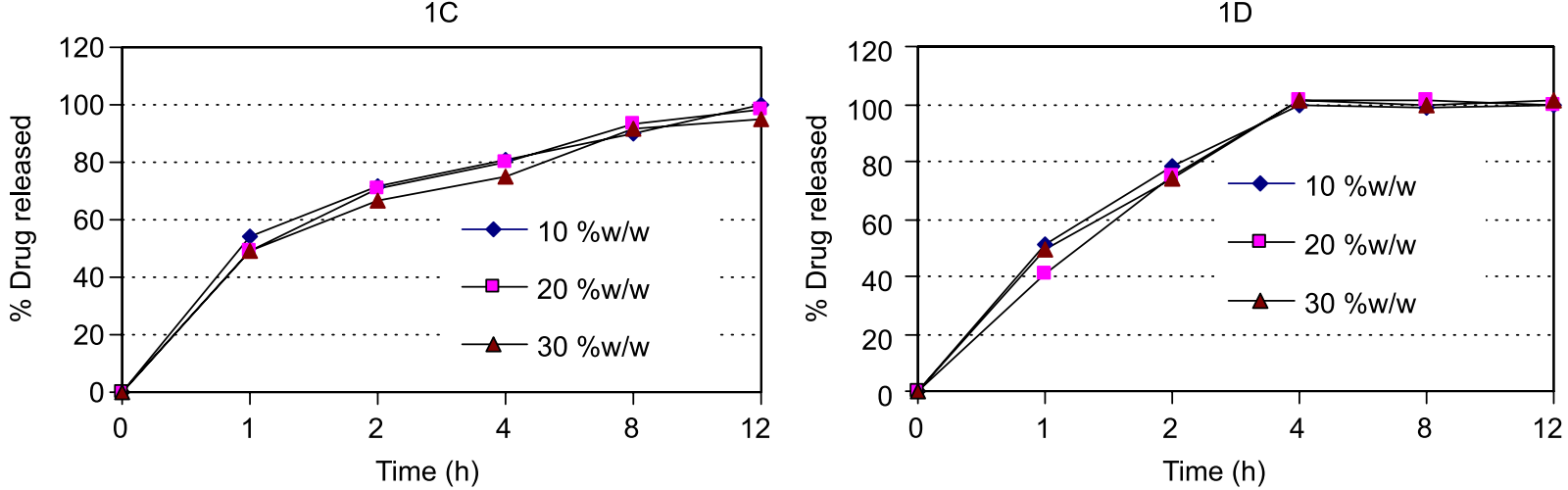

FIGURE 1 - In vitro dissolution profiles of sertraline from pellets containing $10 \% \mathrm{w} / \mathrm{w}, 20 \% \mathrm{w} / \mathrm{w}$ and $30 \% \mathrm{w} / \mathrm{w}$ 1A: Aquacoat ${ }^{\circledR}$ ECD, 1B: Eudragit ${ }^{\circledR}$ NM30D, 1C: Eudragit $^{\circledR}$ L30D 55, 1D: Keltone ${ }^{\circledR}$ LV CR.

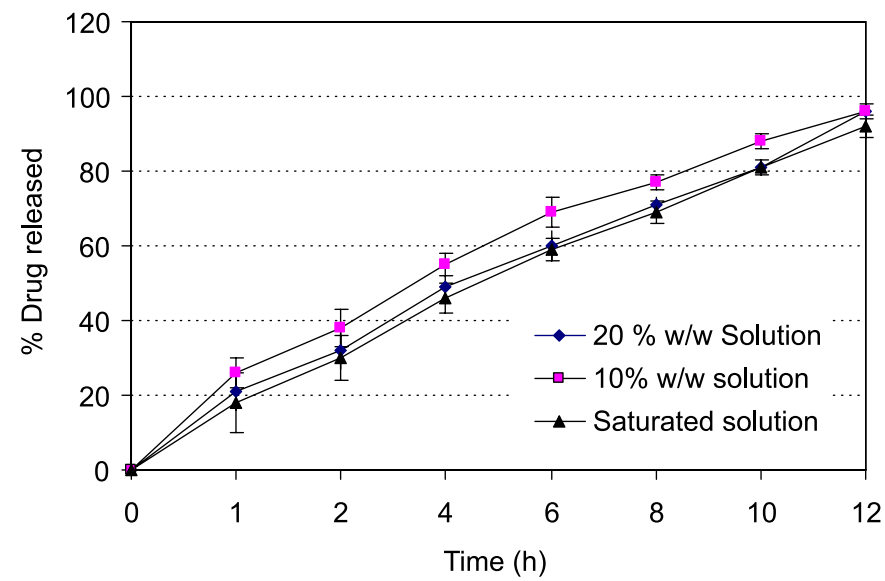

FIGURE 2 - In vitro dissolution profiles of sertraline from calcium alginate pellets treated with (-口-) $10 \% \mathrm{w} / \mathrm{w}$ Calcium chloride solution, (- -$) 20 \% \mathrm{w} / \mathrm{w}$ Calcium chloride solution and (- $\mathbf{\Delta}$-) Saturated calcium chloride solution.

\section{Pellet characterization}

Pellets obtained with all polymers tested showed comparable density, sphericity and friability as compiled in Table III. However, the density of the pellets prepared with sodium alginate was lower compared to pellets obtained from the other polymers. This observation can be attributed to the swelling nature of the alginate in the presence of water during granulation and subsequent increase in porosity upon drying. The process yield of the desired fraction pellet was found to vary with the nature and level of the polymer used. The lowest process yield of $72.2 \%$ was observed while using $10 \% \mathrm{w} / \mathrm{w}$ Eudragit L 30D 55 due to generation of the fines fraction below the ASTM 40 mesh. However, when using 30\%w/w Eudragit NM 30D, the process yield was only $72.8 \%$ with rejection being due to retention of pellets on the upper mesh size (ASTM 20 mesh) given the formation of large (dumb bell shaped) pellets. The process yield from the rest of the polymer levels was comparable. Drug content of the pellets was found to vary from 89 to $93 \% \mathrm{w} / \mathrm{w}$ considering the process loss at various stages during manufacture. The general observation is that the process yield was low due to fines generation when a low level of polymer was used whereas at higher levels of polymer, the process yield was also found to be low as a result of the larger or irregular-shaped pellets generated because of difficulties in spheronization. The shape of the pellets obtained varied 




FIGURE 3 - A. Scanning electron micrographs of pellets prepared using sodium alginate as polymer. B. Calcium chloride-treated pellets.

from spherical to elongated spherical or dumbbell shape in some cases. The lowest sphericity of $65 \%$ was observed in the pellets prepared using higher levels of polymer and the most spherical pellets obtained showed a sphericity value of $88 \%$. The scanning electron micrographs of sodium alginate-containing pellets and calcium chloride-treated matrix pellets are shown in Figure 3.

The surface of the matrix pellets treated with calcium chloride was smoother and uniformly covered with gelatinous mass of calcium alginate. The pellets were almost spherical and no significant morphological differences were observed.

\section{Compression of core pellets into MUPS tablets}

Based on the release profile of the pellets, only calcium chloride-treated pellets were considered for compression into MUPS tablets. For compressing these pellets, microcrystalline cellulose was used as a filler in diluent blend (TAB \#1) because of its cushioning property leading to minimum damage to the pellets during compression. Due to differences in the size and density of both pellets and excipients, weight variation and content uniformity problems are regularly observed during compression of pellets where these could be controlled by carefully selecting pellets with narrow size distribution together with excipients of similar size and shape. The composition of the extra granular blend was prepared using different grades of microcrystalline cellulose and evaluated for content uniformity. In one of the approaches, part of the microcrystalline cellulose was milled and replaced the original composition (Table II). Based on this, to obtain uniformity in drug content within the compressed tablets by maintaining a minimum size difference, pellet fractions passed through ASTM \# 20 mesh and retained over \#40 mesh were used. The direct compression approach was used to obtain disintegrating tablets where the pellets were mixed with microcrystalline cellulose, crospovidone (PPXL) to achieve fast disintegration with polyethylene glycol used as the cushioning agent at the ratio (Table I) shown in Table II. Percentage of pellets in the composition was maintained at a $30 \% \mathrm{w} / \mathrm{w}$ level based on previous studies involving compression of blends containing pellets from $30 \% \mathrm{w} / \mathrm{w}$ to $40 \% \mathrm{w} / \mathrm{w}$ of the composition (Lundqvist, Podczeck, Newton, 1998) that yielded satisfactory results. Tablets were compressed on a single rotary compression machine using one set of tooling and carefully adjusting the gap between the turret and the feed frame to avoid pellet entrapment and subsequent physical damage. The tablets with the optimized composition were compressed at different compression forces $(2-6 \mathrm{kN})$ to obtain an average crushing strength of $80 \mathrm{~N}$ to $240 \mathrm{~N}$ and evaluated for physical and release characteristics as depicted. Increasing the compression force increased hardness and extended disintegration time but led to lower friability as depicted in Table IV. This phenomenon might be attributed to the formation of more condensed compact with increased compression force. However, hardness showed no impact on the drug release pattern as the tablets were disintegrating into individual pellets in the dissolution vessels. As the overall composition contained a large fraction of microcrystalline cellulose, the effect of crospovidone and polyethylene glycol level was found to have minimal impact on the disintegration time of the tablets hence the dissolution profile. 
TABLE IV - Physical characterization data of compressed tablets using optimized composition

\begin{tabular}{lccccc}
\hline Composition & $\begin{array}{c}\text { Compression Force } \\
(\mathrm{kN})\end{array}$ & $\begin{array}{c}\text { Hardness } \\
(\mathrm{N})\end{array}$ & $\begin{array}{c}\text { Thickness } \\
(\mathrm{mm})\end{array}$ & $\begin{array}{c}\text { Friability } \\
(\% \mathrm{w} / \mathrm{w})\end{array}$ & $\begin{array}{c}\text { Disintegration } \\
\text { Time }(\mathrm{s})\end{array}$ \\
\hline TAB \#2 & $2-3$ & $80-120$ & $6.4 \pm 0.1$ & 0.86 & 45 \\
& $3-5$ & $120-180$ & $6.6 \pm 0.1$ & 0.32 & 75 \\
& $5-6$ & $180-240$ & $6.8 \pm 0.1$ & 0.11 & 150 \\
\hline
\end{tabular}

\section{Comparison of release from uncompressed pellets and MUPS tablets}

Sodium alginate pellets (Figure 3 ) treated with calcium chloride solution were compressed into disintegrating tablets using the compositions listed in Table II, at an optimum crushing strength of $160 \mathrm{~N}$, and were evaluated by in vitro drug release studies. A dissolution study of six tablets was conducted as per the specified method and the release profile compared with uncompressed pellets (Figure 4).

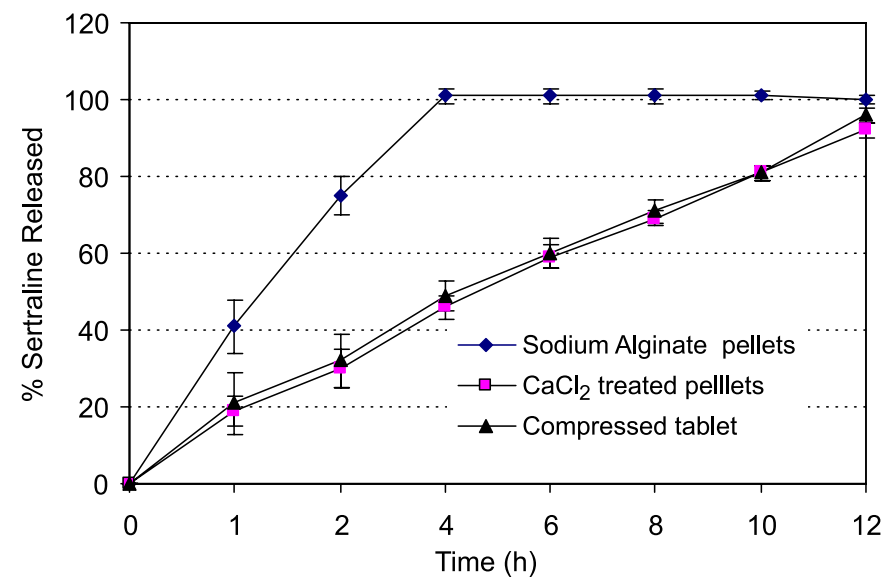

FIGURE 4 - In vitro dissolution profiles of sertraline from pellets containing (- - ) $20 \% \mathrm{w} / \mathrm{w}$ plain sodium alginate, (-口-) Calcium chloride-treated pellets and (- $\mathbf{\Delta}-)$ compressed tablets.

The release profile of the MUPS tablets was identical to the release from the uncompressed pellets. The similarity in the release profiles could be attributed to the absence of a thin film of rate-controlling polymer as in the case of reservoir type pellets which are prone to damage during applied compression forces. In the present study, each pellet was presumed to behave like a monolithic matrix mini tablet distributed within the cushioning diluent blend where the drug release was not dependent on the status and nature of the extended release film. The pellets positioned on the surface of the tablet were visually inspected using a magnifying glass for any physical deformities on the pellet surface. Individual pellets subjected to compression force through direct contact with the tooling surface were slowly segregated manually and observed under scanning electron microscope. From the scanning electron micrographs, segregated pellets were found to be physically modified with loss of spherical shape due to flattening of the part of the surface being pressed in the direction of the applied force (Figure 5).

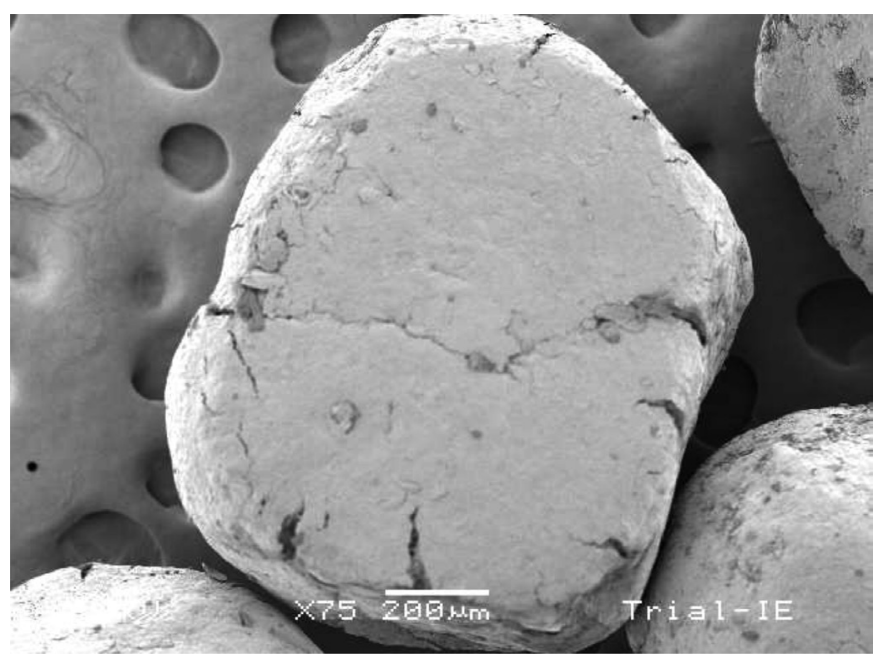

FIGURE 5 - Scanning electron micrograph of segregated individual pellet from the tablet surface directly exposed to the tooling surface during compression.

However, minor physical deformities or changes in shape are not expected to have significant impact on the release profile of the matrix pellets. This can be attributed to the presence polymer uniformly distributed within each pellet and whenever pellets encounter minor damage during compression, polymer within the pellet would still control drug release. Hence, only negligible alterations in drug release from both uncompressed pellets and the tablets were observed. Scanning electron micrographs (Figure 6) of the tablets showed well-distributed pellets in the diluent blend where pellets remained separate from each other preventing fusion and formation of non-disintegrating matrix mass. Pellets were intact and no pellets were found to be fragmented by the applied compression force within the diluent blend. This was possible by keeping the pellet 
percent at $30 \% \mathrm{w} / \mathrm{w}$ where individual pellets remained well separated and protected from the compression deformities.

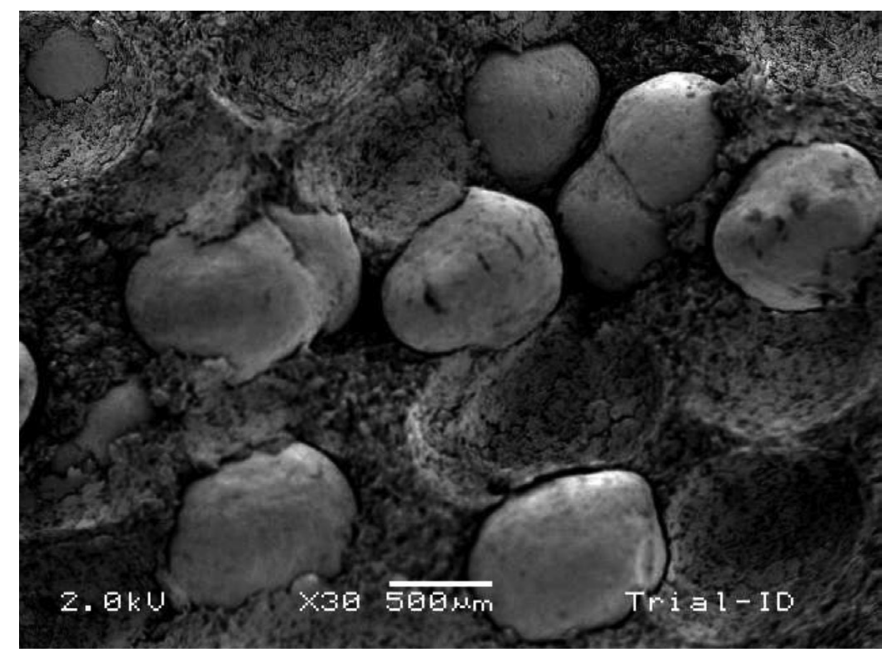

FIGURE 6 - Scanning electron micrograph of compressed tablet indicating distribution of matrix pellets within the diluent blend.

\section{Content uniformity and Acceptance Value (AV)}

In the present study, content uniformity of the ten compressed tablet was evaluated by measuring the sertraline content in individual tablets. The acceptance value of the compressed tablet was found to be 18.7 for TAB \#1 composition containing Avicel PH 102 only as the filler. The higher AV indicates the poor ability of Avicel PH102 in preventing segregating tendency as previously reported (Beckert, Lehmann, Schmidt, 1998). The variation in the content can be due to the differences between density and size of the pellets compared to the diluent blend $(0.4 \mathrm{~g} / \mathrm{cc})$ which may cause segregation of the pellets. Moreover, when compressing the tablets using a single punch on a 12-station compression machine, the residence time of the blend in the feed frame is longer hence the possibility of preferential movement of the pellets into the die cavity increases, leading to variation in pellet uniformity within the tablets.

\section{Influence of Filler on AV}

To evaluate the effect of filler, three different compositions (TAB \# 1-3) were tried as shown in Table 2. In the composition TAB $\# 2$, around $30 \% \mathrm{w} / \mathrm{w}$ of Avicel PH 102 was replaced with Avicel PH 101 and the blend compressed into tablets reducing the AV value to 12.2. In another approach, $30 \%$ of Avicel PH 102 was milled (18R, Quadro comill, at high speed) and Avicel PH 101 was replaced with the milled microcrystalline cellulose wherein the AV value was 14 . This phenomenon of ob- taining lower acceptance values could be attributed to the combination of free flowing (PH 102) and poorly flowing (PH 101 or milled) excipient in the diluent blend which might restrict the preferential movement of the pellets from the blend into the die cavities. Generally, obtaining content uniformity is difficult during compression of pellets into tablets due to various factors other than blend characteristics such as, blend residence time, operational equipment vibrations, number of toolings installed during compression etc. However, we predict a better uniformity with the TAB \#2 compositions by running the compression machine with a complete set of tooling.

\section{Influence of extrusion screen aperture size}

To evaluate the influence of screen aperture size, wet mass of the composition \#F11was extruded using $1.0 \mathrm{~mm}, 1.2 \mathrm{~mm}$ and $1.5 \mathrm{~mm}$ screens. These pellets were dried and mixed with extra-granular excipients (TAB \#2) and compressed into MUPS tablets. The tablets showed satisfactory physical characteristics. No significant difference in the dissolution profile of these tablets was observed (Figure 7).

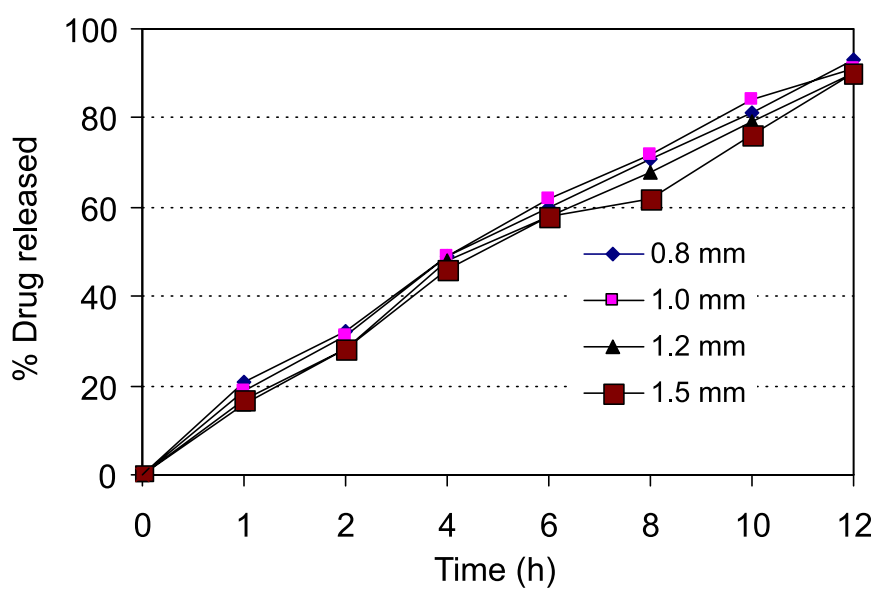

FIGURE 7 - Effect of extruder screen aperture size, (- -) $0.8 \mathrm{~mm},\left(-\square_{-}\right) 1.0 \mathrm{~mm},\left(-\boldsymbol{\Delta}_{-}\right) 1.2 \mathrm{~mm}$ and (-口-) $1.5 \mathrm{~mm}$, on in vitro sertraline release.

However, as the pellet size increased, the AV value was found to rise due to increased segregation tendency of the pellets (Figure 8). Based on this study, a screen aperture size of $0.8 \mathrm{~mm}$ was considered most suitable for extrusion of pellets to be compressed into tablets.

\section{Influence of Pellet Percentage $(\% w / w)$ in the composition}

Pellet proportion in the composition was increased from $30 \%$ to $40 \%$ and $60 \% \mathrm{w} / \mathrm{w}$ by replacing the filler 




FIGURE 8 - Effect of extrusion screen aperture size $(0.8 \mathrm{~mm}$, $1.0 \mathrm{~mm}, 1.2 \mathrm{~mm} \& 1.5 \mathrm{~mm}$ ) on Acceptance Value of tablets.

composition. Accordingly, tablet weight was reduced (Table II) and compressed using suitable tooling. Tablets showed satisfactory physical characteristics. However, there was significant impact on the in vitro dissolution profile in the tablets (Figure 9).



FIGURE 9 - Effect of pellet percentage $(-\downarrow-) 30 \% \mathrm{w} / \mathrm{w}$, (-口-) $40 \% \mathrm{w} / \mathrm{w}$ and (- $\boldsymbol{\Delta}-$ ) $60 \% \mathrm{w} / \mathrm{w}$ in tablet composition on $i n$ vitro sertraline release.

There was no significant difference in the drug release profile of the tablets containing $30-40 \% \mathrm{w} / \mathrm{w}$ pellets. At these levels, the tablets showed comparable physical characteristics and disintegration times. However, the tablets containing $60 \% \mathrm{w} / \mathrm{w}$ pellet failed to behave like rapidly disintegrating tablets in the dissolution vessels. As the percentage of pellets was increased, pellets were distributed closer in the diluent blend and underwent deformation leading to fusion of pellets into a non-disintegrating pellet mass consequently reducing drug release. This is in accordance with previous studies, confirming that tablets containing pellets below $60 \% \mathrm{w} / \mathrm{w}$ showed satisfactory results (Debunne et al., 2004).

\section{Stability study evaluation of compressed tablets}

MUPS tablets prepared using sodium alginate (calcium chloride treated) pellets were subjected to stability study and evaluated for drug content and in vitro release profile. No significant change in the drug content was observed $(99.2 \% \mathrm{w} / \mathrm{w})$ compared to its initial assay content $(98.9 \% \mathrm{w} / \mathrm{w})$, respectively for the tablets prepared using sodium alginate-containing pellets. In vitro release profile of the tablets after completing the $3 \mathrm{M}$ accelerated stability study was studied and results are given in Figure 10.

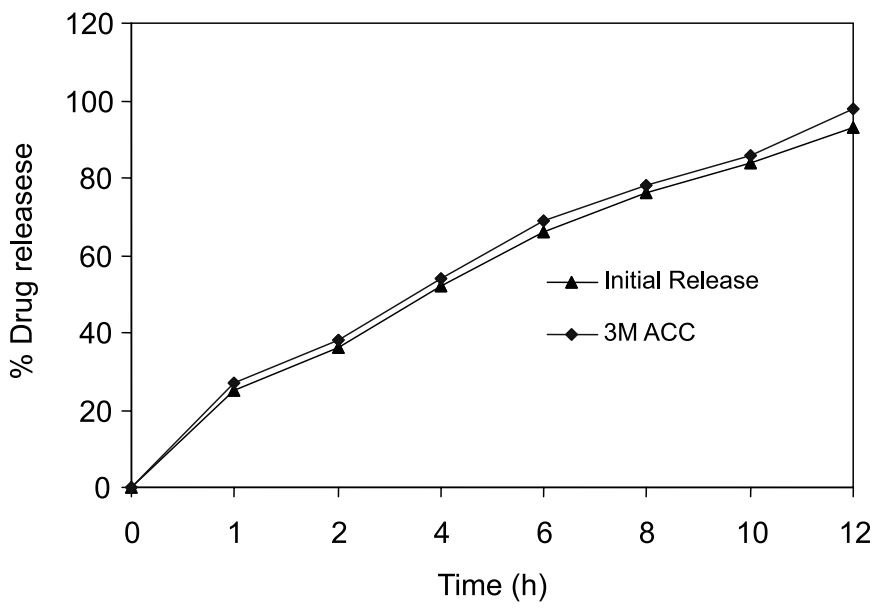

FIGURE 10 - In vitro drug release profile of tablets prepared using Sodium alginate-containing pellets during stability evaluation.

\section{CONCLUSION}

Using various polymers, matrix pellets were successfully prepared. The desired drug release was achieved from the alginate-containing pellets treated with saturated solution of calcium chloride. The drug release from matrix pellets and compressed tablets using these pellet was found to be similar. Acceptance value was easily achieved using a combination of Avicel PH 102 and Avicel PH 101 as fillers in the diluent blend. Further, the extrusion/spheronization technique can be explored to prepare extended release matrix type pellets which can substitute reservoir-type pellets in preparing the MUPS tablets. Future research could be dedicated to exploring other techniques to obtain greater uniformity of drug content in MUPS tablets.

\section{REFERENCES}

BANSAL, P.; VASIREDDY, S.; PARIKH, D. Effect of compression on the release properties of polymer coated niacin granules. J. Control. Release, v.27, p.157-163, 1993. 
BAER, L.; REMNON, J.P. Influence of amount of granulating liquid on the drug release rate from pellets made of extrusion/spheronization. Int. J. Pharm., v.95, p.135-141, 1993.

BECHGAARD, H.; NIELSEN, G.H. Controlled release multiple units and single unit doses. Drug Dev. Ind. Pharm., v.4, p.53-57, 1978.

BHAGAT, H.R.; MENDES, R.W.; MATHIOWITZ, E.; BHARGAVA, H.N. Novel self-correcting membrane coating technique. Pharm. Res., v.8, p.576-583, 1990.

BECKERT, T.E.; LEHMANN, K; SCHMIDT, P.C. Compression of enteric coated pellets to disintegrating tablets: uniformity of dosage units. Powder Technol., v.96, p.248-254, 1998.

BRANKA, I.; SVETLANA, I.; GABRIELE, B.; ZORICA, D. Evaluation of Diclofenac sodium release from Matrix pellets compressed into MUPS tablets. Yaugaku Zasshi, v.129, p.1375-1384. 2009.

BODMEIER, R. Tableting of coated pellets. Eur. J. Pharm. Biopharm., v.43, p.1-8. 1997.

CURATOLO, W.J; THOMBRE, A.G; FERGIONE M.B; ROY, M.C; APPEL, A.L; FRIESEN, D.T; FRIESEN, M.B; BEYERINCK, R.A. Hydrogel-driven layered dosage form. Patent No. US 6,899,896 B2: 2005.

DASHEVSKY, A.; KOTLER, K.; BODMEIER, R. Compression of pellets coated with various aqueous polymer dispersions. Int. J.Pharm., v.279, p.19-26. 2004.

DEBUNNE, A.; VERVAET, C.; MANGELINGS, D; REMON, J.P. Compaction of enteric-coated pellets: influence of formulation and process parameters on tablet properties and in vivo evaluation. Eur. J. Pharm. Sci., v.22, p.305314, 2004.

DOGAN, D.P. Toleration and safety of sertraline: experience world wide. Int. Clin. Psychopharmacol., v.6, s.2, p.47-56, 1991.

ERIKSSON, M.; NYSTROM, C.; ALDEBORN, G. The use of air permeability for assessment of external surface area and sphericity of pelletized granules. Int. J. Pharm., v.99, s.197, p.197-207, 1993.
FLAMENT, M.P.; LETERME, P.; GAYOT, A.; GENDROT, E.; BRUNA, E. Development and industrial scale-up of tablets containing modified release pellets. Pharm. Tech. Eur., v.6, p.9-25, 1994.

GRIMSLEY, S.R.; JANN, M.W. Paroxetine, sertraline and fluvoxamine: new selective serotonin reuptake inhibitors. Clin. Pharm., v.11, p.930-957, 1992.

HARRIS, M.R.; SELLASSIE, I.G. Aqueous polymeric coating for modified release pellets. In: MCGINITY, J.W. (Ed.). Aqueous polymeric coatings for pharmaceutical dosage forms. New York: Marcel Dekker, 1989. p.63-79.

HELTON, S.; FRANCISCO, V.M.; EUGENIA, P.; JOAO, J.S. Compaction, compression and drug release properties of diclofenac sodium and ibuprofen pellets comprising xanthan gum as sustained release agent. Int. J. Pharm., v.295, p.15-17, 2005.

HODSDON, A.C.; MITCHELL, J.R.; DAVIES, M.C.; MELIA, C.D. Structure and behavior in hydrophilic matrix sustained release dosage forms: 3 . The influence of $\mathrm{pH}$ on the sustained-release performance and internal gel structure of the sodium alginate matrices. J. Control. Release, v.33, p.143-152, 1995.

LOVGREN, K.; LUNDBERG, P. Determination of Sphericity of pellets prepared by extrusion/spheronization and the impact of some process parameters. Drug Dev. Ind. Pharm., v.15, p.2375-2392, 1989.

LUNDQVIST, A.E.K.; PODCZECK, F.; NEWTON, J.M. Compaction of and drug release from, coated drug pellets mixed with other pellets. Eur. J. Pharm. Biopharm., v.46, p.369-379, 1998.

LEONARD, B.E. The comparative pharmacology of new anti depressants. J. Clin. Psychiatry, v.54, s.8, p.3-15, 1993.

LOPEZ-RODRIGUEZ, F.J.; TORRADO, S.; ESCAMILLA, C.; CADORNIGA. R.; AUGSBURGER, L.L. Compression behavior of acetylsalicylic acid pellets. Drug Dev. Ind. Pharm., v.19, p.1369-1377, 1993.

MURTHY DWIBHASHYAM, V.S.N.; VIJAYA RATNA. Key formulation variable in tableting of coated pellets. Ind. $J$. Pharm. Sci., v.70, p.555-564, 2008. 
PAI, R.; KOHLI, K. Extended release matrix pellets: preparation and compression into disintegrating tablet. Int. J. Drug Del., v.3, p.329-339, 2011.

PORNSAK, S.; JURAIRAT, N.; MANEE, L.; SATIT, P. Alginatebased pellets prepared by extrusion /spheronization: A preliminary study on the effect of additive in granulating liquid. Eur. J. Pharm. Biopharm., v.67, p.227-235, 2007.

PATEL, H.K.; NAGLE, A.; MURTHY, R.S.R. Characterization of calcium alginate beads of 5-flurouracin for colon delivery. Asian J. Pharm., v.2, p.241-245, 2008.

TORRADO, J.J.; PARONEN, P. Effect of different excipients on the tableting of coated particles. Int. J. Pharm., v.10, p.149-155, 1994.

UNITED STATES PHARMACOPEIA. 28 ed. Baltimore: The United states Pharmacopeial Convention, 2007. v.30, n.905. p.378-382.
SARISUTA, N.; PUNPREUK, K. In vitro properties of filmcoated diltiazem hydrochloride pellets compressed into tablets. J. Control. Release, v.31, p.215-222, 1994.

SRIAMORNSAK, P.; KENNEDY, R.A. Development of polysaccharide gel coated pellets for oral administration. 2. Calcium alginate. Eur. J. Pharm. Sci., v.29, p.139-147, 2006.

WIESLAW, S.; JAROSLAW, M.; ILONA, J. Hot tabletting of slow release tramadol hydrochloride microcapsules with cores obtained via compaction. Drug Dev. Ind. Pharm., v.32, p.209-217, 2010.

Received for publication on $23^{\text {rd }}$ June 2011 Accepted for publication on $19^{\text {th }}$ September 2011 